\title{
PATOLOGIAS EM ESTRUTURAS DE CONCRETO ARMADO: UM ESTUDO DE CASO DA PONTE RIO CHOPIM.
}

\author{
GÖTTEMS, CLÁUDIA VIVIANE \\ Estudante \\ Centro Universitário de Pato Branco-UNIDEP \\ Paraná; Brasil \\ civil.gottems@gmail.com
}

\author{
CAMICIA, RODRIGO JUNIOR DA MOTTA \\ Engenheiro Civil \\ Centro Universitário de Pato Branco-UNIDEP \\ Paraná; Brasil \\ rodrigo.camicia@unidep.edu.br
}

\author{
OLIVEIRA, LUCAS \\ Estudante \\ Centro Universitário de Pato Branco-UNIDEP \\ Paraná; Brasil \\ eng_civil.oliveira@hotmail.com
}

\section{RESUMO}

O concreto armado é formado basicamente de concreto e aço, que pode apresentar problemas originados de falhas na execução, materiais utilizados, e falta de manutenção. Como um exemplo de estrutura em concreto armado, têm-se as pontes que estão sujeitas a variadas ações, podendo comprometer sua funcionalidade, ocasionando sua deterioração e envelhecimento, devido ao uso contínuo e a falta de programas de manutenção. O presente artigo tem como objetivo analisar as manifestações patológicas encontradas em uma determinada estrutura, através de um estudo de caso na ponte sobre o Rio Chopim, localizada entre os municípios de Pato Branco-PR e Coronel Vivida-PR, onde fora realizado uma análise comparativa entre os dados obtidos por meio de visita in loco, com os dados do relatório do DNIT em 2014. Na visita realizaram-se registros fotográficos das fissuras e eflorescência encontradas nas lajes, dos pilares, tubulões e vigas que apresentavam falhas na concretagem e desplacamento do concreto, tornando as armaduras expostas, das cortinas de cada lado da ponte. Após a coleta e análise visual das imagens, pode-se constatar que não foi realizado nenhum reparo na estrutura após a vistoria realizada, e que a mesma não apresentou grandes evoluções, apesar disso, é notável a necessidade de realizar reforços e reformas para que os problemas da estrutura não se agravem, pois a mesma encontrase exposta a intempéries climáticas, aumentando assim sua vida útil.

Palavras-chave: manifestações patológicas, pontes, manutenção.

\begin{abstract}
Reinforced concrete is basically formed of concrete and steel, which can present problems originated from failures in the execution, materials used, and lack of maintenance. As an example of reinforced concrete structure, there are bridges that are subject to various actions, which can compromise its functionality, causing its deterioration and aging, due to continuous use and lack of maintenance programs. This article aims to analyze the pathologies manifestations found in a given structure, through a case study on the bridge over the Chopim River, located between the municipalities of Pato Branco-PR and Coronel Vivida-PR, where a comparative analysis was performed between the data obtained through on-site visits, with the data from the DNIT report in 2014. During the visit, photographic records were made of the cracks and efflorescence found in the slabs, columns, tubulons and beams that showed faults in concrete casting and paving, making the reinforcement exposed, of the curtains on each side of the bridge. After collecting and visually analyzing the images, it can be seen that no repair was made to the structure after the inspection, and that it did not present major developments, despite this, it is notable the need to make reinforcements and reforms so that the problems of the structure are not aggravated, because it is exposed to the weather, thus increasing its useful life.
\end{abstract}

Keywords: pathological manifestations, bridges, maintenance. 


\section{INTRODUÇÃO}

O concreto armado é uma prática utilizada nas construções das estruturas, formada por concreto e aço, mas com o decorrer do tempo esta estrutura pode apresentar manifestações patológicas, que afetam o desempenho e qualidade nas estruturas, reduzindo a resistência à ruptura, a capacidade de suportar as influências externas e, consequentemente, sua vida útil.

As patologias surgem depois de erros de projetos, escolha incorreta de materiais, falhas na execução e manutenção das estruturas (FERREIRA, 2018).

Segundo a NBR 6118:2014 - Norma Projeto de Estruturas de Concreto - Procedimento, as estruturas de concreto devem atender a requisitos mínimos de qualidade durante a execução dos serviços. Sendo dividido em três grupos distintos, quais sejam: a capacidade de resistência à ruptura, o desempenho em serviço que consiste na capacidade da estrutura manter-se em boas condições durante sua utilização, sem que apresente danos que comprometam em parte ou totalmente o seu uso e para o qual foi projetada, e a durabilidade que consiste na capacidade da estrutura resistir às influência ambientais que são previstas durante a elaboração do projeto (ABNT, 2014).

A elaboração deste trabalho justifica-se pelo grande número de problemas que ocorrem em todo o mundo e em diversas obras de engenharia, isso devido ao crescimento acelerado da construção civil. Com isso é necessário buscar por inovações e maior conhecimento sobre materiais e comportamento das estruturas. A escolha por realizar o presente estudo vem da importância de saber a origem das manifestações patológicas para poder evitá-las ou reduzi-las através de monitoramento em todas as etapas da obra, do planejamento, da mão de obra qualificada, do uso de materiais de boa qualidade, da realização das manutenções que são necessárias com o decorrer do tempo.

A presente pesquisa foi realizada na ponte sobre o Rio Chopim, situada entre os municípios de Pato Branco-PR e Coronel Vivida-PR, com o principal objetivo de verificar as manifestações patológicas existentes na estrutura de concreto armado e posteriormente compará-las com as patologias encontradas em 2014 na vistoria realizada pelo DNIT, além de verificar se os problemas encontrados na época evoluíram e qual é a situação atual dos mesmos encontrados.

\section{REVISÃO BIBLIOGRÁFICA}

\subsection{Patologia}

O termo patologia vem do grego "pathos", que significa doença, e "logia" que se refere a estudo, sendo assim o estudo de anomalias ou alterações de um elemento, os sintomas as causas e as origens dos defeitos ocorridos nas obras. As patologias se manifestam de diversas formas, entre elas estão às fissuras, trincas, rachaduras, entre outras. Em alguns casos é possível realizar o diagnóstico através da visualização, em outros casos em que o problema é mais complexo, é necessário uma investigação mais aprofundada, analisando o projeto e quais cargas a estrutura foi submetida, analisar como foi executada a obra, como a patologia esta reagindo com determinados estímulos, sendo possível assim identificar quais as causas dos problemas e quais serão as correções necessárias para que o problema não venha mais a ocorrer (ARIVABENE, 2015).

O termo vida útil de projeto é regido pela Norma de Desempenho, NBR 15575:2013, ou seja, a norma determina um prazo legal, onde é de obrigatoriedade mínima, a durabilidade do elemento a ser edificado (ABNT, 2013). Segundo a Norma Ações e Segurança nas Estruturas - Procedimento, NBR 8681:2003, as estruturas devem ter um prazo de vida útil mínimo de 50 anos, porém, conforme o Manual de Recuperação de Pontes e Viadutos, a durabilidade da estrutura de uma ponte, deverá ser igual ou superior a 100 anos (ABNT, 2003; DNIT, 2010).

A vida útil do elemento está intimamente ligada a necessidade do conhecimento das ações de intempéries climáticas, condições locais, e muitas vezes a incoerência nas aplicações dos serviços. Geradores estes das deficiências estruturais, tais como: fissuras, trincas, desplacamento do concreto, nichos no concreto (falhas na concretagem), eflorescências, abrasão e recalque diferencial (BASTOS, 2017). 
É importante citar que as manifestações patológicas podem ser originadas a partir de inúmeros fatores e estes não são diferentes em pontes de concreto armado ou de outro material, portanto, podem-se mencionar os seguintes fatores: envelhecimento, construção acelerada, não respeitando o tempo de cura, estrutura submetida a cargas móveis intensas e projetos deficientes para padrões atuais (DNIT, 2010).

\subsection{Perícia}

A perícia na construção civil é compreendida por uma atividade de avaliação técnica, devendo ser realizada por profissional legalmente habilitado e capacitado para averiguar e esclarecer os fatos, verificar a integridade de um bem, levantar dados que motivaram um evento, aferi-lo, se promove risco a vida útil do elemento. É um conjunto de atividades que são desenvolvidas com o objetivo de conservar e recuperar a função de uma edificação, atendendo as necessidades e promovendo maior segurança aos usuários (PRESOTTO, 2017).

\subsection{Fissuras}

A fissura é o elemento resultante da fragilidade do concreto na tração, e que pode colapsar e romper de forma repentina (SOUZA, 1998). Geralmente existem várias possibilidades do concreto fissurar, dentre elas destacam-se: a retirada precoce das formas, a relação água/cimento, a segregação dos agregados, e os nichos no concreto. Mas o que há em comum na causa da fissuração, raramente incide em outra região a não ser na região de tração, ou seja, abaixo da linha neutra.

Para Bastos (2017), as fissuras podem ocorrer por erros no dimensionamento ou falhas no detalhamento do projeto, ocasionando erros na execução. As fissuras podem diminuir a vida útil de uma estrutura pois pode comprometer sua utilização e segurança, ocasionando prejuízos no funcionamento e na estética dos elementos estruturais, além de causar corrosão da armadura quando esta estiver exposta a ações agressivas do ambiente.

\subsection{Trincas}

O fator determinante para apontar uma trinca é evidenciado pela "separação entre o elemento", podendo ser uma viga, laje, pilar e até mesmo na alvenaria. São aberturas que variam de $0,5 \mathrm{~mm}$ até $1,0 \mathrm{~mm}$ (ARIVABENE, 2015). As trincas são agravantes das fissuras, surgindo devido a falta de manutenção e correção da sua predecessora, demonstrando que o elemento apresenta falhas na sua execução, ou até mesmo no seu projeto de dimensionamento (SOUZA, 1998).

\subsection{Desagregação do concreto}

A desagregação do concreto, para Souza (1998), pode ocorrer por diversos fatores, na maioria das vezes em conjunto com as fissuras. É uma separação física que ocorre no concreto e está relacionada com fatores como a perda das características na relação agregados em conjunto com a diminuição da função ligante do cimento. Pode-se afirmar que este acontecimento apresenta indícios patológicos ao demonstrar mudanças na coloração, indicando a existência de um ataque químico, onde o cimento perde seu aglomerante e os agregados ficam livres da união proporcionada pela pasta de cimento, além de ocorrer o aumento na abertura das fissuras (DNIT, 2010).

\subsection{Abrasão e falhas na concretagem}

A abrasão do concreto, é uma manifestação patológica muito incidente em obras como pontes e viadutos. Considerando-se a perda gradativa da massa de concreto superficial devido a sua exposição às ações do intemperismo, ou seja, o desgaste superficial possui inúmeros agentes, sendo a água e o ar os dois mais comuns, e que acabam provocando a erosão do concreto (SOUZA, 1998).

No entanto, surge outro tipo de patologia ocasionada pelo desgaste do elemento, segundo Bastos (2017), a cavitação, que consiste em pequenas cavidades, resultante de águas correntes, ocorrendo com maior frequência em tubulões submersos em rios. 
Diferentemente da abrasão e da cavitação, que também apresentam nichos e corrosão da massa de concreto, a falha de concretagem é a maior preocupação, pois ocorre durante a execução dos serviços, podendo ocorrer a segregação dos agregados com a pasta de cimento. Suas deficiências podem ser geradas por alguns fatores, como por exemplo, o transporte, lançamento, juntas de concretagem, entre outros (ARIVABENE, 2015).

\subsection{Corrosão da armadura}

A corrosão das armaduras ocorre devido a inúmeros fatores, estando presente na maioria das estruturas de concreto armado. São causadas principalmente devido aos esforços resultantes das fissuras, que irá permitir com mais facilidade a entrada de agentes agressivos através dos vazios (OLIVEIRA, 2018).

Segundo Arivabene (2015), a corrosão incide em 20\% do total das manifestações patológicas apresentadas em uma obra, e se tratando de um evento brando e de aumento exponencial, pode-se considerar uma das mais graves nas estruturas de pontes. Para Bastos (2017), após a oxidação da armadura ocorre a expansão de seu volume em até 8 vezes, ocasionando a expulsão da zona de cobrimento deixando assim a armadura exposta.

\subsection{Infiltrações, manchas, bolor ou mofo e eflorescência}

As infiltrações ocorrem pelo contato excessivo de uma estrutura com o ambiente fluvial, ou encontra-se em locais bastante úmidos, ocorrendo a penetração da água no elemento, devido ao concreto ser propenso a conter vazios e fissuras (FELIX, 2018).

Com o componente estrutural aderindo o acumulo de água, formam-se manchas, e a partir destas, origina-se o bolor ou mofo, que são o acúmulo de fungos originários de vários substratos (varia com o meio), e apresentam manchas escuras, na tonalidade preta, marrom e verde (ARIVABENE, 2015).

As eflorescências aparecem devido ao acúmulo de umidade, resultado dos agentes do próprio cimento, os componentes alcalinos, que salinizam e eflorescem de dentro para fora, ocasionando na região uma perda das resistências, as lixiviações e sua apresentação são indesejáveis por razões estéticas (DNIT, 2010).

\section{METODOLOGIA}

A presente pesquisa teve como finalidade a realização de um estudo de caso, através da coleta de informações das manifestações patológicas encontradas na ponte de concreto armado situada sobre o Rio Chopim, localizada entre os municípios de Pato Branco-PR e Coronel Vivida-PR. A partir dos conceitos abordados realizou-se a análise documental e exploratória para identificar as patologias existentes na ponte.

Para melhor compreendermos os problemas e dar seguimento a pesquisa, foi realizada visita in loco com o intuito de verificar a superestrutura da ponte, e realizar os registros fotográficos das manifestações patológica, baseando-se nas patologias identificadas em 2014 por peritos e especificadas através do relatório disponibilizado pelo DNIT Pato Branco-PR.

Após a averiguação e coleta das informações, foram analisadas as imagens das manifestações encontradas, e realizado o comparativo com as imagens e dados contidos no relatório de vistoria do DNIT, com o intuito de verificar se houve avanços nas manifestações patológicas contidas na ponte. 
Na Figura 1-A mostra a foto da ponte retirada do relatório acima citado, e a foto 1-B refere-se à ponte atualmente.

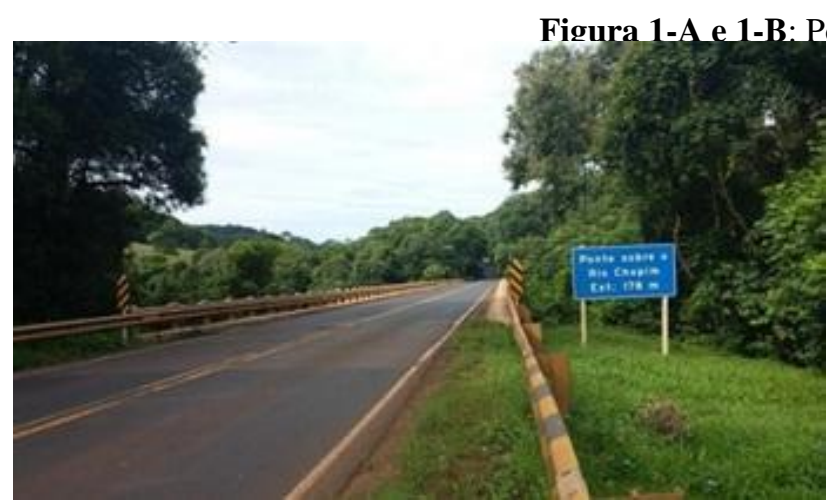

Fonte: DNIT, 2014.

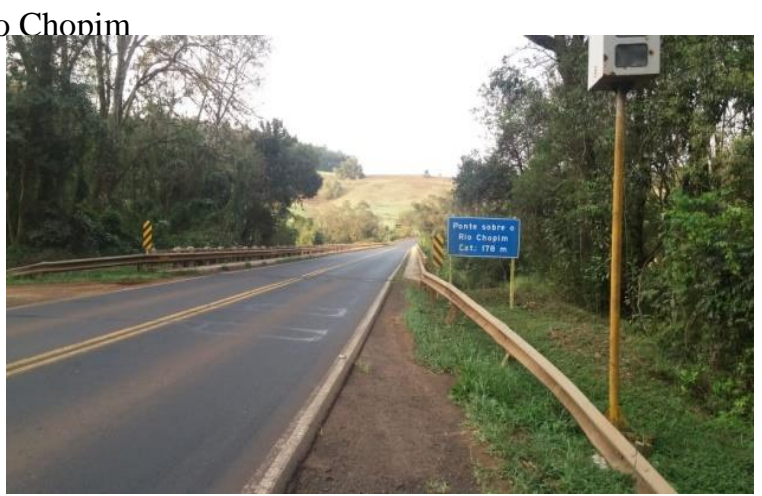

Fonte: Autoria Própria.

Segundo o DNIT (2014), o projeto da ponte foi aprovado em 1984, apresentando as características das pontes projetadas no período de 1960 e 1975, com seção transversal de 10,00 metros, largura da pista de 8,20 metros, dois guarda rodas de 0,90 metros, com dois guarda corpos de 0,15/0,90 metros sobre o guarda rodas. Cargas móveis para veículos de 36 tf e multidão de $0,5 \mathrm{tf} / \mathrm{m}^{2}$ e $0,3 \mathrm{tf} / \mathrm{m}^{2}$. A superestrutura contém 7 vãos e dois balanços totalizando 164,00 metros, as fundações são constituídas de tubulões em concreto armado, o pavimento atual da ponte é o flexível.

\section{RESULTADOS E DISCUSSÕES}

Após a coleta das imagens, foi realizada a análise comparativa, onde na figura 2-A mostra a imagem retirada do relatório do DNIT que demonstra a situação do pavimento na entrada da ponte, lado Pato Branco, e na figura 2-B é a situação atual deste pavimento.

Figuras 2-A e 2-B: Entrada da ponte, lado Pato Branco.

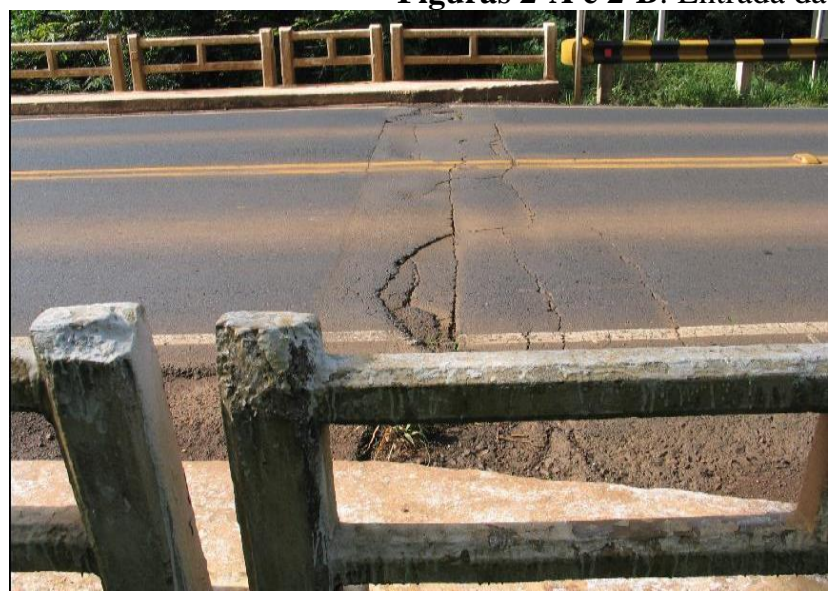

Fonte: DNIT, 2014.

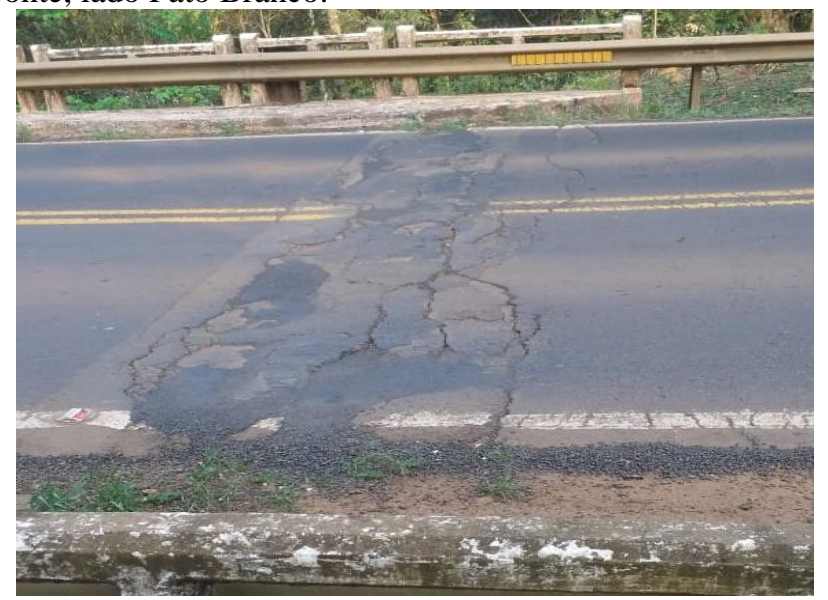

Fonte: Autoria Própria.

Pode-se observar que houve grande alteração durante este período. O provável motivo desta mudança é devido à base do lado Pato Branco estar apoiada indevidamente, ocorrendo assim a movimentação da cortina e retraindo a massa asfáltica constantemente, já que a mesma não possui armadura preventiva para isto, melhor identificada nas Figuras 3-A e 3-B.

Segundo as diretrizes e orientações da NBR 7188:2013 - Carga móvel rodoviária e de pedestres em pontes, viadutos, passarelas e outras estruturas, a solução plausível para este caso é a remoção local da capa de rolamento, aplicar reforço 
estrutural na base (ABNT, 2013). Porém conforme relatos da avaliação do DNIT, a solução empregada pelos engenheiros responsáveis, em longo prazo é a reconstrução total das bases, tanto lado Pato Branco, quanto o lado Coronel Vivida (DNIT, 2014). Antes da inserção de nova capa na pista de rolamento, recomenda-se corrigir as juntas de dilatação da laje com material expansivo e cobrir com pavimento flexível.

A cortina do lado Pato Branco, observada nas Figuras 3-A e 3-B, apresentam armadura exposta, fissuras e rachaduras. Segundo o DNIT (2014), esses problemas ocorreram devido a utilização de pedra marroada de mão na execução da contenção, pois o talude apresenta bastante inclinação. A presença deste material rígido produziu esforços sobre a estrutura da ponte, impedindo seu movimento normal, e ocorrendo o esmagamento do concreto, no entanto, nas análises fotográficas e visuais não constam modificações no colapso da estrutura.

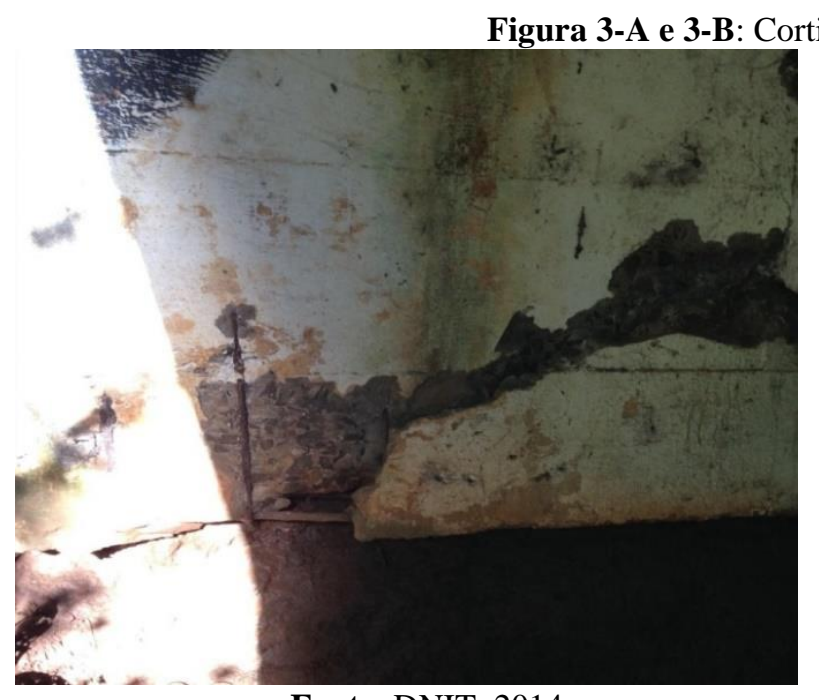

Fonte: DNIT, 2014.

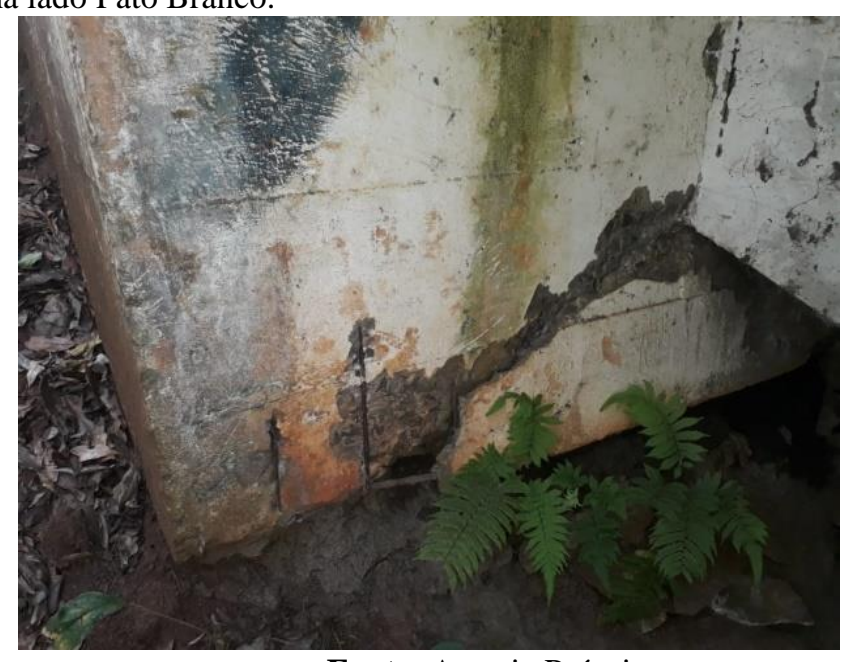

Fonte: Autoria Própria.

A estrutura da base demonstrou que houve movimentação natural da estrutura, colapsando a viga em que se apoia as lajes do pavimento de rolamento. Com esta situação, é necessário a remoção do concreto rompido e desplacado da armadura, realizando-se através de jateamento d'agua sob pressão na superfície a ser recuperada, ou mesmo por meio de cinzeis, ponteiros e rompedores mecânicos. Segundo recomendações do Manual de recuperação de Pontes e Viadutos do DNIT, é previsível que seja feita uma remoção profunda na viga, aproximadamente cinco centímetros adentro da armadura, posteriormente deverá ser aplicado em todo o entorno do aço deteriorado uma solução inibidora de ferrugem, a qual proporciona maior durabilidade ao mesmo, (DNIT, 2010).

Baseando-se na possibilidade de recuperar as vigas da base, a inserção de armaduras auxiliares proporcionaria extinguir maiores agravantes do colapso no local. E para as armaduras adjacentes deverá obter-se conforme projeto de recuperação da estrutura a ser realizado, seguindo diretrizes da NBR 7188 (ABNT, 2013). 
Conforme citado anteriormente, nas Figuras 4-A e 4-B, pode-se observar a inclinação do talude no lado Pato Branco.
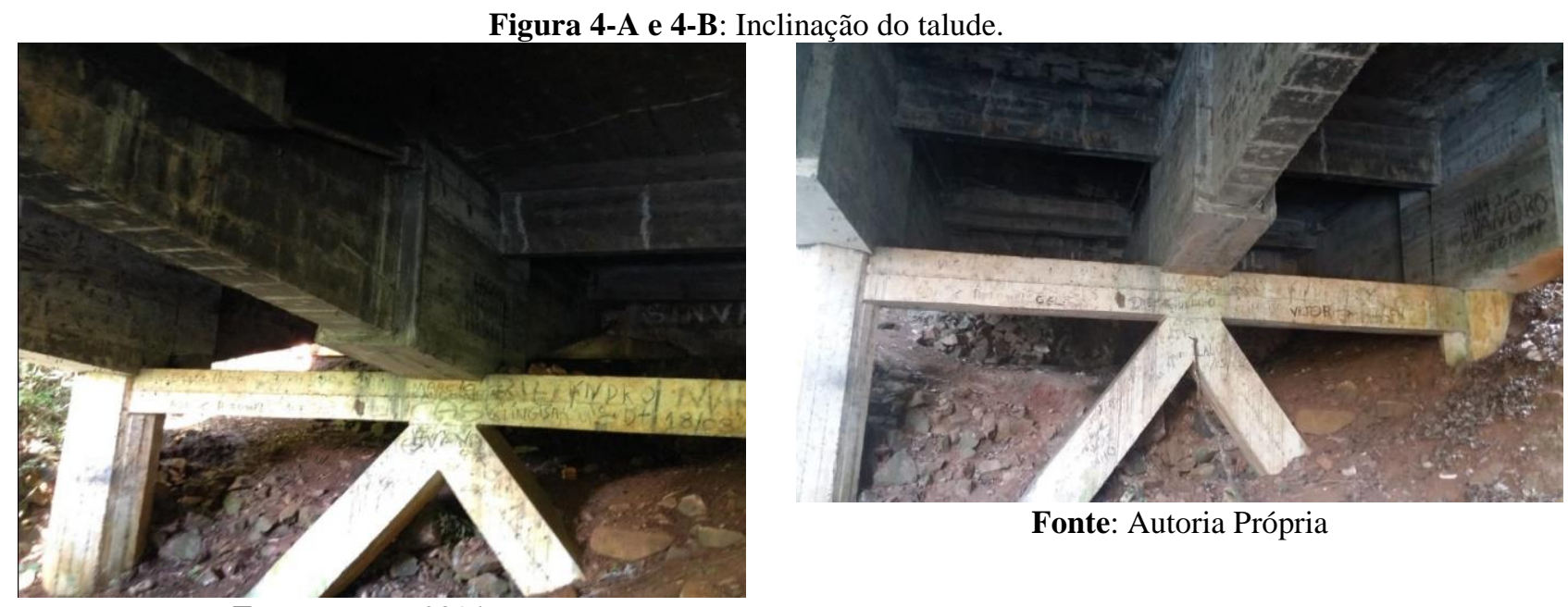

Fonte: Autoria Própria

Fonte: DNIT, 2014

As Figuras 5-A e 5-B mostram a cortina do lado Coronel Vivida apresentando também inclinação.

Figura 5-A e 5-B: Inclinação do talude.

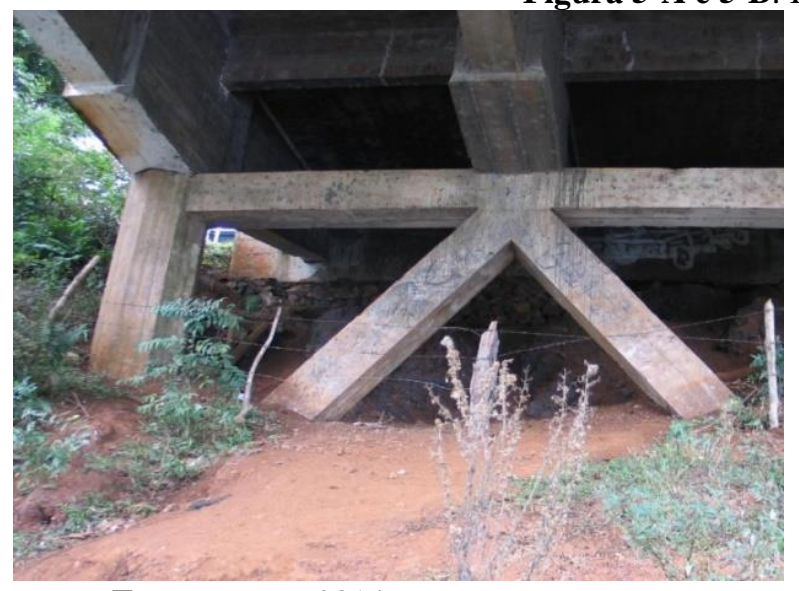

Fonte: DNIT, 2014.

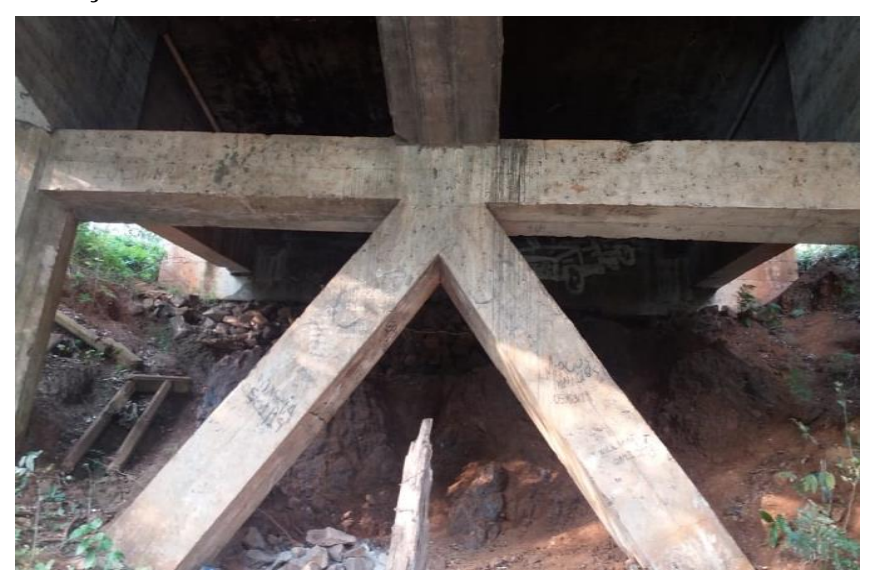

Fonte: Autoria Própria.

Uma das manifestações patológicas mais presentes na estrutura são as armaduras expostas e oxidadas originadas por problemas na execução como, falhas na concretagem e cobrimento insuficiente da armadura, conforme representadas nas Figuras 6-A e 6-B. Percebe-se também a presença de manchas brancas denominadas de eflorescência encontradas nas faces internas das vigas. Através da análise de ambas as fotos pode-se observar que visivelmente não houve evolução no problema apresentado. 
Figura 6-A e 6-B: Armaduras expostas.

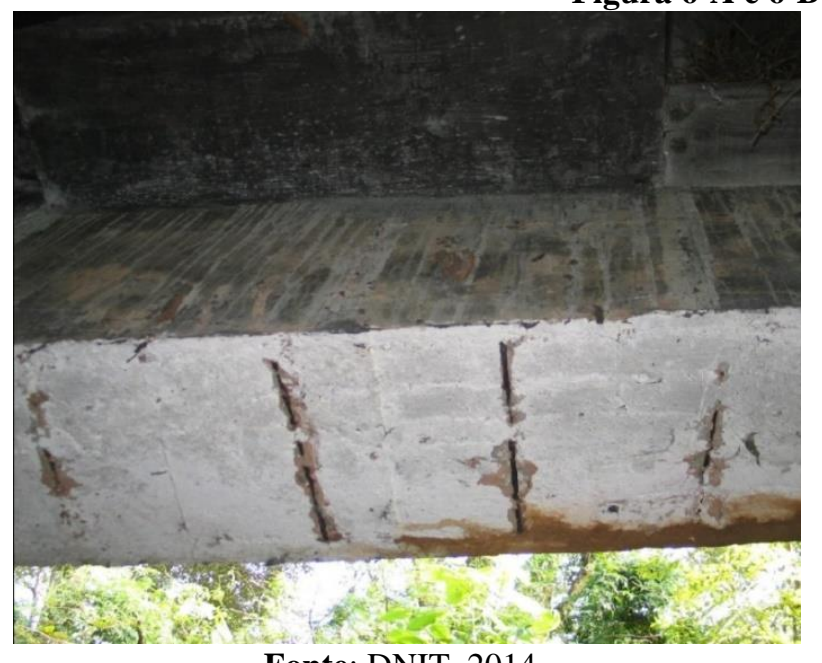

Fonte: DNIT, 2014.

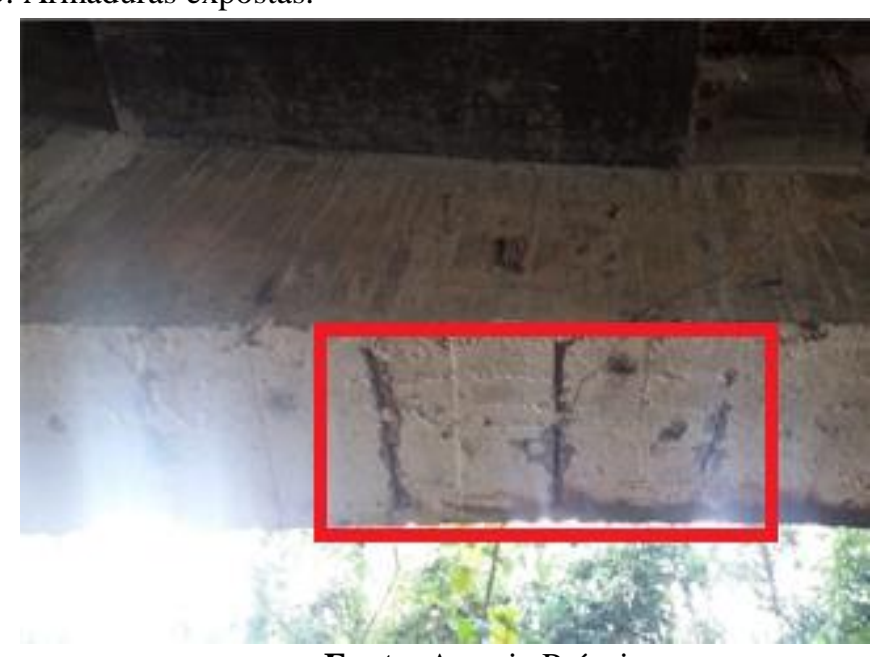

Fonte: Autoria Própria.

No entanto, o indício de armadura exposta com oxidação, provoca a perda de função estrutural da peça e, se tratando de pontes, viadutos e passarelas, o avanço desta manifestação pode resultar no colapso total, ou parcial. Porém, recomenda-se que seja realizada uma análise nessa armadura, para saber se o aço foi corroído e posteriormente realizar tratamentos adequados em toda sua seção e reforço estrutural, caso contrário realizar assoreamento do concreto afetado e a limpeza com auxílio de jatos de alta pressão e limpeza com produtos anticorrosivos, e posteriormente o encobrimento da peça com concreto.

Conforme observado nas Figuras 7-A e 7-B, os tubulões também apresentam falhas na concretagem, armaduras visíveis, ninhos e nichos de concreto, e por estar em contato direto com a água e oxigênio pode tornar a armadura oxidada mais rapidamente. Apresentam também efeitos de abrasão na sua superfície, causada pela exposição às ações do intemperismo. Com tudo, a análise realizada pelo grupo de engenheiros do DNIT em 2014 e a observação das mesmas manifestações realizada neste ano, nota-se que visivelmente não houve mudanças, sendo assim, a correção deste defeito é cabível ao método citado anteriormente.

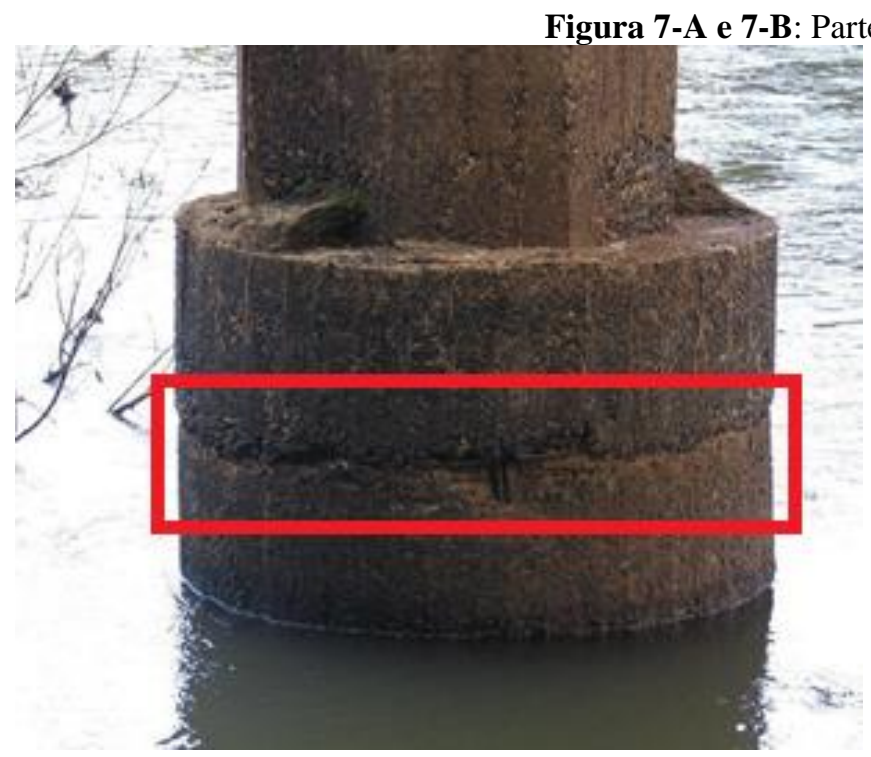

Fonte: DNIT, 2014.

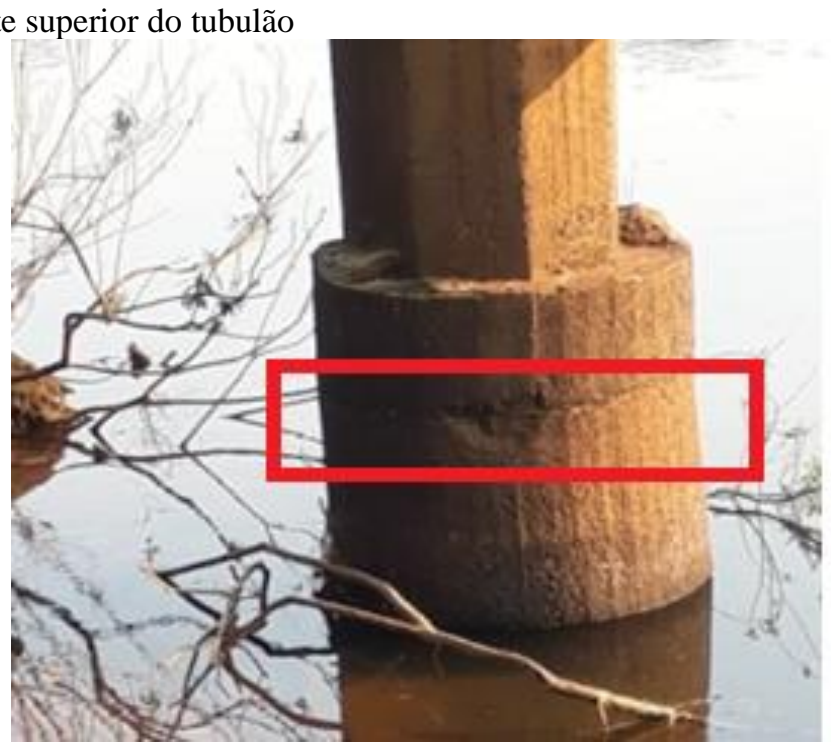

Fonte: Autoria Própria

Anais do Congresso Brasileiro de Patologia das Construções - CBPAT 2020 
As Figuras 8-A e 8-B mostram os apoios, tirantes e escoras com falhas na concretagem, manchas escuras e claras e abrasão, ocorridas devido a estrutura estar exposta a ação da água. Pode-se observar que não foi realizada melhorias, e que aparentemente os problemas não evoluíram.

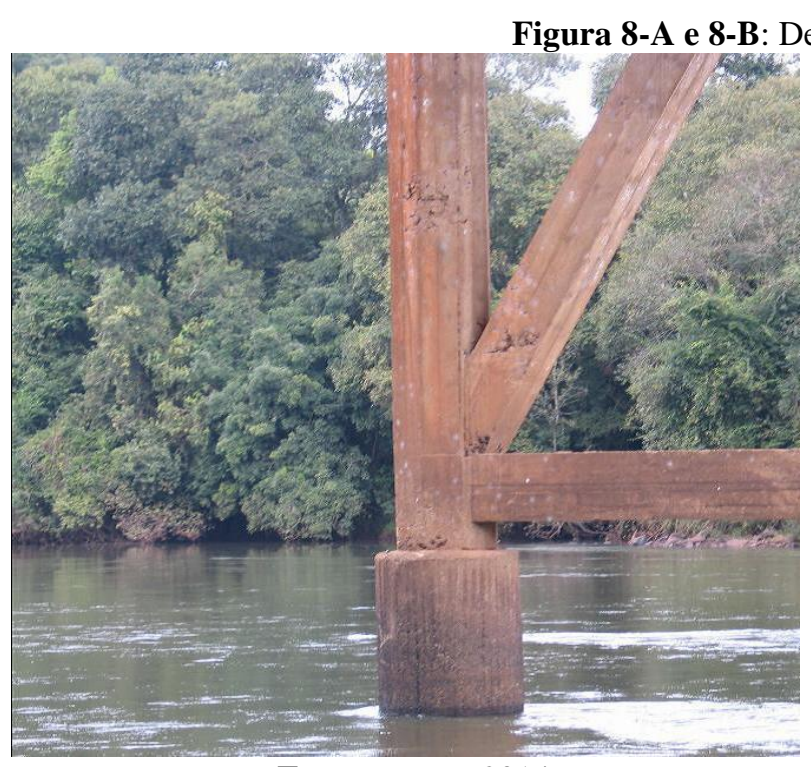

Fonte: DNIT, 2014.

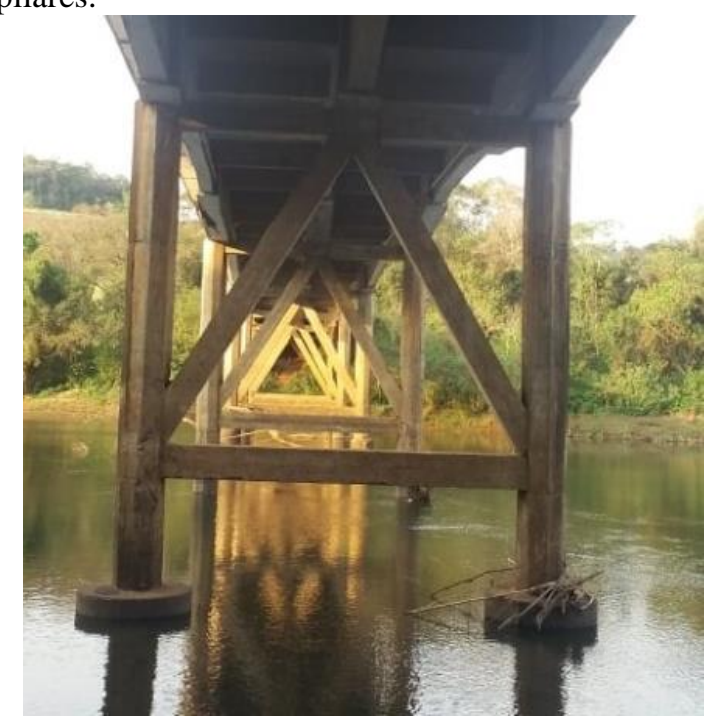

Fonte: Autoria Própria.

Já nas Figuras 9-A e 9-B pode-se observar que a estrutura está livre, não possui material rígido que pudesse impedir a movimentação da estrutura, com isso não apresentou sérios danos, comparado com a outra extremidade. Mas apresenta armadura exposta e oxidada devido ao desplacamento do concreto, comparando as imagens observa-se que não houve diferença neste elemento estrutural.

Figura 9-A e 9-B: Cortina lado Coronel Vivida.

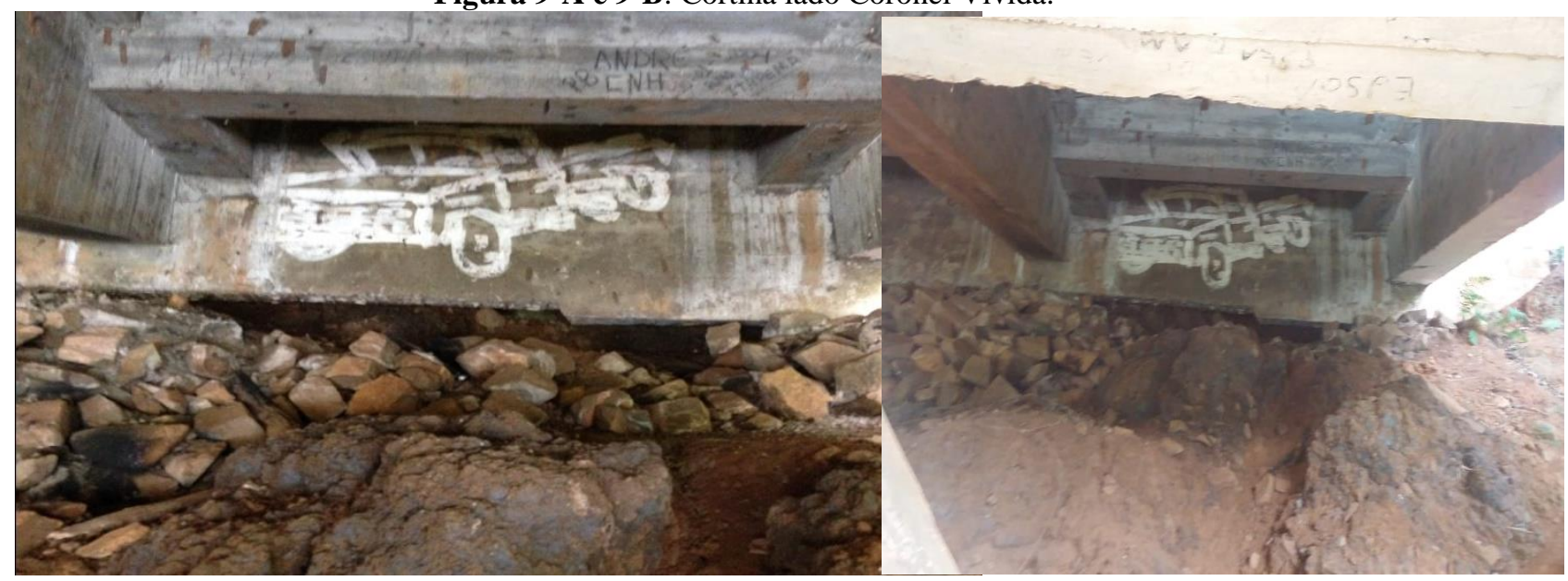

Fonte: DNIT, 2014.

Fonte: Autoria Própria.

As lajes apresentam fissuras e manchas brancas, que ocorrem devido ao acúmulo de umidade conforme observado nas Figuras 10-A e 10-B. Segundo o relatório do DNIT (2014), as fissuras diminuíram após a execução da protensão e injeção da argamassa de resina epoxídica. 
Figura 10-A e 10-B: Fissuras e eflorescência nas lajes.

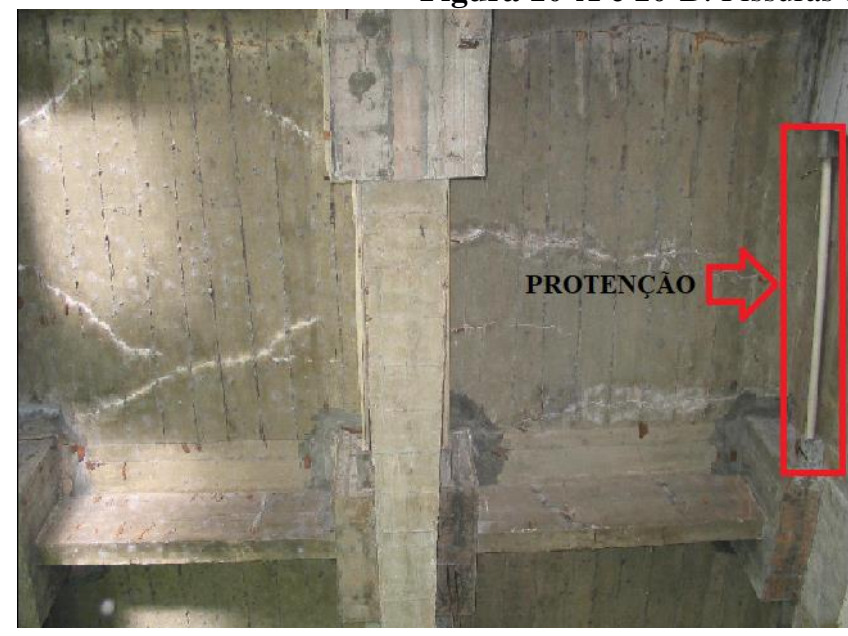

Fonte: DNIT, 2014

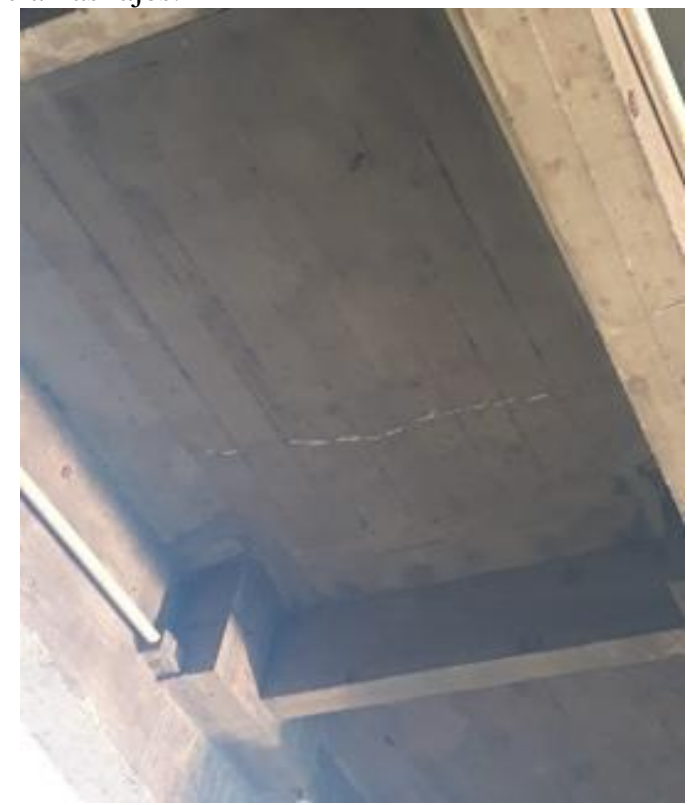

Fonte: Autoria Própria.

As correções explanadas tem se mostrado como eficazes na neutralização das manifestações patológicas identificadas, ou seja, impedindo sua propagação e afloramento de maiores problemas. Porém é válido lembrar a importância da análise periódica destas manifestações na preservação da referida ponte, já que sua reconstrução parcial ou total, acarretaria na inviabilização viária da região e seus entornos, o que ressalta ainda mais a aplicação de meios corretivos à curto prazo aos elementos deteriorados, prolongando sua vida util.

\section{CONSIDERAÇÕES FINAIS}

Diante dos variados mecanismos de deterioração que a estrutura de uma ponte está exposta, é de suma importância que seja realizado um cronograma de manutenção global, para mantê-la em bom estado de conservação e preservação.

Ao analisar a situação das patologias encontradas na estrutura e citadas no presente trabalho, é notável a necessidade de se realizar reparos, para assim garantir maior vida útil e consequentemente maior segurança aos usuários.

Através do comparativo pode-se observar que a maior diferença encontrada foi nas fissuras do pavimento, do lado de Pato Branco originada pela movimentação da base, devido estar apoiada sobre pedras que conhecemos por basalto de calçamento, citadas no relatório DNIT 2014 como pedra marroada, impedindo sua movimentação normal. As armaduras expostas e oxidadas, e as manchas brancas encontradas nas vigas não sofreram alterações visivelmente, assim como nos tubulões que apresentaram armaduras expostas e oxidadas, ninhos e nichos de concreto e o efeito de abrasão.

Nos apoios, tirantes, e escoras apresentaram falhas na concretagem, manchas escuras e claras, e abrasão. Nas lajes apresentou fissuras e eflorescência e na cortina lado Pato Branco apresentou armadura exposta, fissuras e rachaduras, não exibindo diferença visual.

Como sugestão de melhoria, a base lado Pato Branco deverá passar por uma avaliação aprofundada sobre o problema para verificar se resolveria realizar apenas um reforço na estrutura, ou se tem a necessidade de um novo projeto para a cortina, conforme citado no relatório de vistoria do DNIT. 
Para que os elementos estruturais que apresentam armaduras expostas e oxidadas tenham seus efeitos patológicos interrompidos, tem-se como solução inicial a remoção do concreto deteriorado, a limpeza das armaduras oxidadas e o cobrimento com nova capa de concreto, podendo ser contribuída com reforço estrutural, se esse for necessário.

Nota-se através do relatório DNIT, que a aplicação de resina epóxi nas fissuras e a inserção dos cabos de protensão, diminuíram a propagação das fissuras no pano de laje da ponte. Com isso podemos afirmar que devido a esta correção não houve um agravamento significativo nas fissuras, deixando evidente a importância da realização de manutenção.

Considerando que a ponte foi projetada em 1984 com as características das pontes projetadas no período de 1960 e 1975, encontra-se com diversos problemas devido na época as cargas móveis serem menores do que atualmente, e por não ter sido realizado manutenções preventivas durante todos esses anos.

Futuramente pode ser realizado um estudo mais aprofundado nas patologias encontradas na ponte, com o intuito de verificar a gravidade de cada problema e poder corrigi-los de maneira mais eficiente, e a montagem de um cronograma de manutenção adequado para garantir maior vida útil a esta estrutura.

\section{REFERÊNCIAS}

ARIVABEne, ANTONIO CESAR. Patologias em Estruturas de Concreto Armado: Estudo de Caso. Vitória-ES: Editora especialize, 2015.

BASTOS, HERICK CÉSAR DO NASCIMENTO; MIRANDA, MATEUS ZANIRATE. Principais patologias em Estruturas de Concreto de Pontes e Viadutos: Manuseio e Manutenção das Obras de Arte Especiais. Belo Horizonte-MG, Revista Construindo, 2017.

DNIT - DEPARTAMENTO NACIONAL DE INFRAESTRUTURA DE TRANSPORTES. Manual de Recuperação de Pontes e Viadutos Rodoviários. Rio de Janeiro, 2010.

DNIT - DEPARTAMENTO NACIONAL DE INFRAESTRUTURA DE TRANSPORTES. Relatório de Vistoria Ponte S/Rio Chopim. Rodovia: BR - 158/PR. Brasília-DF, 2014.

FELIX, E.F. et al. Análise Numérica da Deformação de Elementos de Concreto Armado devido à Ação da Corrosão Uniforme. Campo Grande-MS, 2018.

FERREIRA, RICARDO. Patologias em Estruturas de Concreto Armado. Monte Carmelo-MG, 2018.

NBR 6118 - ASSOCIAÇÃO BRASILEIRA DE NORMAS TÉCNICAS (ABNT). Projeto de Estruturas de Concreto

- Procedimento. Rio de Janeiro, 2014.

NBR 7188 - ASSOCIAÇÃO BRASILEIRA DE NORMAS TÉCNICAS (ABNT). Carga Móvel Rodoviária e de Pedestres em Pontes, Viadutos, Passarelas e outras Estruturas. Rio de Janeiro, 2013.

NBR 8681 - ASSOCIAÇÃO BRASILEIRA DE NORMAS TÉCNICAS (ABNT). Ações e Segurança nas Estruturas Procedimento. Rio de Janeiro, 2003.

NBR 15575 - ASSOCIAÇÃO BRASILEIRA DE NORMAS TÉCNICAS (ABNT). Norma de Desempenho. Rio de Janeiro, 2013.

OLIVEIRA, TALITA DE SOUZA; CARDOSO, ANA CAROLINA SARAIVA. Deformação Lenta das Estruturas de Concreto Armado e Suas Manifestações Patológicas. Revista de Engenharia e Tecnologia, 2018.

PRESOTTO, MARIA IZABEL MILlANI, et al. Pericias de Engenharia na Construção Civil - Estudo de Caso. Paraná, Revista Técnico-Cientifica do CREA-PR, 2017. 


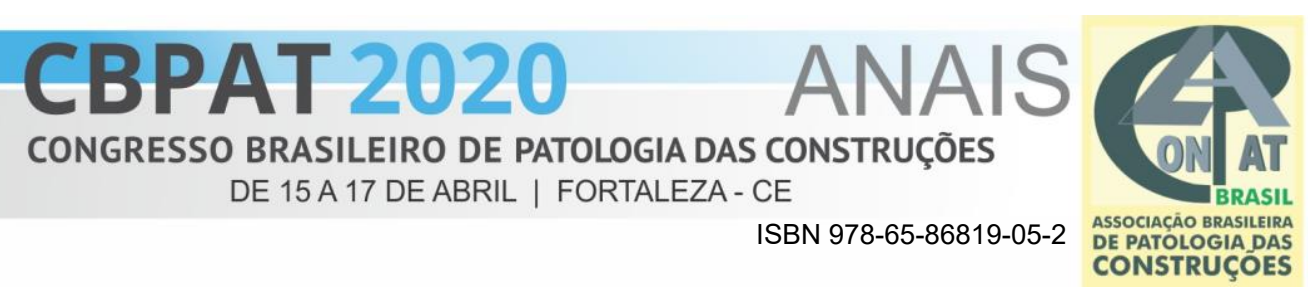

SOUZA, VICENTE C. M.; RIPPER, THOMAZ. Patologia, Recuperação e Reforço de Estruturas de Concreto. São Paulo, Pini, 1998. 